\title{
Psychiatric Disorders Induced by Abuse of Non-Addictive Substances: An Original Finding
}

\section{Jamshid Ahmadi*}

Fatemeh Ghanizadeh Kazerooni, Department of Psychiatry, Iran

${ }^{*}$ Corresponding author: Jamshid Ahmadi, Professor and Founding Director, Substance Abuse Research Center, Shiraz University of Medical Sciences, Shiraz, Iran, Tel: +98-71-3627 93 19; E-mail: Jamshid_Ahmadi@yahoo.com

Received: Dec 28, 2015; Accepted: Feb 01, 2016; Published: Feb 06, 2016

Copyright: (C 2016 Ahmadi J. This is an open-access article distributed under the terms of the Creative Commons Attribution License, which permits unrestricted use, distribution, and reproduction in any medium, provided the original author and source are credited.

\section{Abstract}

Background: Psychiatric disorders evoked by uncommon substances are progressing.

Objective: To investigate the link between abuse of peculiar substances and psychiatric disorders.

Results: This report displays association of abuse of unusual substances such as antibiotics and psychiatric disorders.

Discussion: This study indicates that non addictive substances and drugs such as antibiotics; gastric acid blockers; corticosteroids and pain killers can induce psychiatric disorders for example mood disorder. Hence these findings could be a considerable addition to the literature.

Conclusions: It looks that not only addictive substances such as opioids, cannabis and methamphetamines may induce psychiatric problems but also non-addictive substances such as antibiotics, corticosteroids, and analgesics could induce psychiatric disturbances.

Keywords: Abuse; Antibiotics; Psychiatric disorders

\section{Introduction}

Substances like heroin that was earlier presented as a nonaddictive derivative form of opium is an opioid mu receptor agonist [1].

Opium has been used up for a long time and has a history of medical, recreational and societal approval in wide compartments of the world, such as Asia, North America and Europe [1-3].

Opioids such as tramadol, codeine and methadone are pure agonist of opioid mu receptor [1], but buprenorphine is a partial agonist and has ceiling, so its utilization has reduced possibility of overdose and also has less physical dependence. Methadone and buprenorphine diminish the incidence of HIV and other problems which are consequences of opiate dependency. Opioids such as methadone is absorbed sufficiently after oral administration but buprenorphine is well absorbed after sublingual utilization, coming to $60 \%-70 \%$ of the plasma concentration, but poorly absorbed while used orally [4-10].

Today, prevalence of medical and mental diseases is climbing in the globe [11-29].

In mental health disorders, substance connected disorders are going up [30-69] and have caused more referrals to outpatient centers and hospitals [70-110].

Now we are reporting a patient with psychiatric disorder related to abuse of non-addictive substances. To the authors' knowledge, there are scanty published reports on this content, so, this description could reveal a novel finding.

\section{Patient Presentment}

MR was a single, 28 years old farmer with secondary school education. He lived with his parents in Kazeroon city of Fars province in south Iran.

He bit by bit started smoking of tobacco and opium at age of 18. Since 8 years prior to this hospital admission he had a car accident with trauma to his left ankle. Then, he increased consumption of substances and gradually began abusing of tramadol, methadone, clonazepam, alprazolam and alcohol. Since 3 years prior to admission MR started smoking heroin. He step by step decreased the dose of narcotics and began abusing of antibiotics such as metronidazole (10 tablets/d), amoxicillin (4 capsules/d), cephalexin (2 capsules/d), ciprofloxacin (2 capsules/d), cotrimoxazole (2 tablets/d); gastric acid blockers such as pantoprazole (2 tablets/d); corticosteroids such as dexamethasone (few tablets/d) and pain killers such as novafen ( 3 capsules/d) since 2 years prior to admission. He did not declare history of IV drug injection. Since 2 years prior to admission, he slowly developed amnesia, depressed mood, hopelessness, anxiety, agitation and irritability.

Due to the named symptoms MR was admitted in psychiatric ward. 
Tests of serology for viral markers (HIV, HCV and HB Ag) were normal. Urine drug screening tests were positive for morphine and benzodiazepine.

In comprehensive psychiatric interview and precise examinations MR was hopeless, depressed, restless, anxious and irritable. In physical and neurological examinations there were not any abnormal findings.

Based on the medical, psychiatric, and substance use history and also DSM-5 criteria, he was supposed as poly substance evoked mood disorder and poly substance dependent.

Patient received sodium valproate $200 \mathrm{mg}$, olanzapine $5 \mathrm{mg}$, methadone $10 \mathrm{mg}$ and diazepam $20 \mathrm{mg}$ per day.

Patient was taking medications and his condition was improving every day.

\section{Discussion}

Iranian drug program expresses that while individuals are found to be using illegal substances, such as opium, heroin, morphine, marijuana, hashish, methamphetamine, cocaine and hallucinogens (tobacco products are legal), they must be referred to treatment units, outpatient centers, private clinics or psychiatric hospitals to be treated.

In Iran, substance dependents for instance opioid dependents are commonly detoxified and treated with methadone, clonidine and sometimes with buprenorphine.

This report illuminates that non addictive substances and drugs such as antibiotics (metronidazole, amoxicillin, cephalexin, ciprofloxacin, cotrimoxazole); gastric acid blockers (pantoprazole); corticosteroids (dexamethasone) and pain killers (novafen) can induce psychiatric disorders for example mood disorder. Hence these findings could be a considerable addition to the literature.

\section{Conclusions}

It can be concluded that not only addictive substances such as opioids, cannabis and methamphetamines may induce psychiatric problems but also non-addictive substances such as antibiotics, corticosteroids, and analgesics could induce psychiatric disturbances.

\section{References}

1. Sadock B, Sadock V, Ruiz P (2015) Kaplan \& Sadock'S Synopsis of Psychiatry: Lippinott Wiliams and Wilkins, Philadelphia (USA).

2. Brian J (1994) Opium and infant-sedation in 19th century England. Health Visit 67: 165-166.

3. Jonnes J (1995) The rise of the modern addict. Am J Public Health 85: 1157-1162.

4. Jasinski DR, Pevnick JS, Griffith JD (1978) Human pharmacology and abuse potential of the analgesic buprenorphine: a potential agent for treating narcotic addiction. Archives of General Psychiatry 35: 501-516.
5. Ling W, Charuvastra C, Collins JF, Batki S, Brown LS, et al. (1998) Buprenorphine maintenance treatment of opiate dependence: a multicenter, randomized clinical trial. Addiction 93: 475-486.

6. Ling W, Rawson RA, Compton MA (1994) Substitution pharmacotherapies for opioid addiction: from methadone to LAAM and buprenorphine. J Psychoactive Drugs 26: 119-128.

7. Strain EC, Stitzer ML, Liebson IA, Bigelow GE (1994) Comparison of buprenorphine and methadone in the treatment of opioid dependence. Am J Psychiatry 151: 1025-1030.

8. Johnson RE, Jaffe JH, Fudala PJ (1992) A controlled trial of buprenorphine treatment for opioid dependence. JAMA 267: 2750-2755.

9. Lewis JW (1985) Buprenorphine. Drug Alcohol Depend 14: 363-372.

10. Jasinski DR, Fudala PJ, Johnson RE (1989) Sublingual versus subcutaneous buprenorphine in opiate abusers. Clin Pharmacol Ther 45: 513-519.

11. Gill D, Ahmadi J, Pridmore S (2014) Suicide and Gambling on the Public Record. MJP 2: 81-88.

12. Ahmadi J, Galal Ahmed M, Ali Bayoumi F, Abdul Moneenum A, Alshawa $H$ (2012) Mental health of dubai medical college students. Iran J Psychiatry Behav Sci 6: 79-83.

13. Ahmadi J, Kamel M, Ahmed MG, Bayoumi FA, Moneenum AA (2008) Dubai, Medical College students' scores on the Beck Depression Inventory. Iranian Red Crescent Journal (IRCMJ) 10: 169-172.

14. Pridmore S, Mclnerney G, Ahmadi, Rybak M(2007) Enlarged Virchow-Robin spaces in a psychotic woman, Journal of Psychiatric Intensive Care 3: 49-54.

15. Pridmore S, Robinson J, Ahmadi J (2007) Suicide for scrutinizers. Australas Psychiatry 15: 247-248.

16. Ghanizadeh A, Kianpoor M, Rezaei M, Rezaei H, Moini R, et al. (2008) Sleep patterns and habits in high school students in Iran. Ann Gen Psychiatry 7: 5.

17. Ghanizadeh A, Arkan N, Mohammadi MR, Ghanizadeh-Zarchi MA, Ahmadi J (2008) Frequency of and barriers to utilization of mental health services in an Iranian population. East Mediterr Health J 14: 438-446.

18. Pridmore S, Ahmadi J (2010) Two cases of 'Type 3' suicide. Australas Psychiatry 18: 426-430.

19. Pridmore $S$, Brüne $M$, Ahmadi J, Dale J (2008) Echopraxia in schizophrenia: possible mechanisms. Aust N Z J Psychiatry 42: 565-571.

20. Pridmore S, Ahmadi J, Majeed ZA (2011) Suicide in Old Norse and Finnish folk stories. Australas Psychiatry 19: 321-324.

21. Auchincloss S, Pridmore S (2013) Usage of 'download of psychiatry' in Africa. Afr J Psychiatry (Johannesbg) 16: 325.

22. Sleep Quality among Patients with Mild Traumatic Brain Injury: A Cross-Sectional Study (2015). Bull Emerg Trauma 3: 93-96.

23. Pridmore S, Ahmadi J (2015) Psalm 137 and Middle Cerebral Artery Infarction; ASEAN Journal of Psychiatry $16: 2$.

24. Pridmore S, Ahmadi J (2005) Book reviews. Aust N Z J Psychiatry 39: 205-6.

25. Pridmore S, Ahmadi J, Evenhuis M (2006) Suicide for scrutinizers. Australas Psychiatry 14: 359-364. 
26. Khademalhosseini Z, Ahmadi J, Khademalhosseini M (2015)Prevalence of Smoking, and its Relationship with Depression, and Anxiety in a Sample of Iranian High School Students. Enliven: Pharmacovigil Drug Saf 1: 005.

27. Mackay-Smith M, Ahmadi J (2015) Pridmore S, Suicide In Shooting Galleries. ASEAN Journal of Psychiatry 16: 50-56.

28. Ahmadi J, Ahmadi N, Soltani F, Bayat F (2014) Gender differences in depression scores of Iranian and german medical students. Iran J Psychiatry Behav Sci 8: 70-73.

29. Ahmadi J, Ghafoori F, Rahimi S (2015)Management of heroin addiction with baclofen and clonidine. Int J Res Rep 1: 6-10.

30. Ahmadi J, Sahraian A, Shariati S (2015) Homicidal patient with major depressive disorder companion with opium dependence: A new arcade. Int J Res Rep 1: 1-5.

31. Ahmadi J (2015) Heroin Dependency Treatment: A New Approach. J Addict Depend 1: 1-3.

32. Ahmadi J (2015) Hashish-Induced Olfactory Hallucination: A Novel Finding. J Psychiatry 18: 330.

33. Ahmadi J (2015) Excellent Outcome of Psychosis Induced by Methamphetamine Intoxication after 20 Sessions of Electro Con-vulsive Therapy. J Addict Depend 1: 1-2.

34. Ahmadi J, Ekramzadeh S, Pridmore S (2015) Remission of Methamphetamine-Induced Withdrawal Delirium and Craving After Electroconvulsive Therapy. Iran J Psychiatry Behav Sci 9: e1793.

35. Ahmadi J, Sahraian A, Dastgheib SA, Moghimi E, Bazrafshan A (2015) Treatment of heroin abuse. Sch Acad J Biosci 3: 966-968.

36. Ahmadi J, Sahraian A, Dastgheib SA, Mani A, Mowla A, et al. (2015) ECT and methamphetamine psychosis: IJMPS 7: 51-53.

37. Ahmadi J (2015) Tramadol Dependency Treatment: A New Approach. J Addict Med Ther Sci 2: 001-003.

38. Ahmadi J, Dehghanian I, Razeghian Jahromi L(2015) Poly substance induced psychosis Sch. J App Med Sci 3: 2693-2695.

39. Ahmadi J, Dehghanian I, Razeghian Jahromi L (2015) Substance induced disorder. Sch J App Med Sci 3: 2700-2703.

40. Therapy in The Management of Methamphetamine Induced Psychosis With Onset During Intoxication (2015) J Addict \& Depend 1:1-3

41. Ahmadi J (2015) The Effect of Buprenorphine and Bupropion in the Treatment of Methamphetamine Dependency and Craving. $\mathrm{Br} J$ Med \& Med Res $10: 1-4$

42. Ahmadi J, Sahraian A, Dastgheib SA, Mowla A, Ahmadzadeh L (2015) Management of Methamphetamine-Induced Psychosis by 8 sessions of ECT Sch. J AppMed Sci 3: 1565-1566.

43. Ahmadi J, Amiri A, Ghanizadeh A, Khademalhosseini M, Khademalhosseini Z, et al. (2014) Prevalence of Addiction to the Internet, Computer Games, DVD, and Video and Its Relationship to Anxiety and Depression in a Sample of Iranian High School Students. Iran J Psychiatry Behav Sci 8: 75-80.

44. Ahmadi J, Soltani F, Tabatabaee F (2014) Substance Use Disorders in Patients with Lung or Heart Diseases. Sch J App Med Sci 2: 111-120.

45. Ahmadi J, Sharifi M (2013) Lifetime and Current Prevalence of Tobacco Smoking. J Addict Res Ther 4: 145.

46. Ahmadi J, Ahmed MG (2013) Dubai Medical College Students' Attitudes towards Substance Use. J Addict Res Ther S6: 005.
47. Ahmadi J, Keshtkar M, Pridmore S (2011) Methamphetamine induced synesthesia: a case report. Am J Addict 20: 306.

48. Ahmadi J, Naghshvarian M1, Afshari R1 (2011) Opioids use in male population referred for mandatory urine opioid screen before marriage in shiraz-iran. Iran J Psychiatry Behav Sci 5: 126-130.

49. Ahmadi J, Kampman KM, Oslin DM, Pettinati HM, Dackis C, et al. (2009) Predictors of treatment outcome in outpatient cocaine and alcohol dependence treatment. Am J Addict 18: 81-86.

50. Ahmadi J, Benrazavi L, Babaeebeigi M, Ghanizadeh A, Ghanizadeh $M$, et al. (2008) Substance use in a sample of medical patients. J Psychoactive Drugs 40: 315-319.

51. Ahmadi J, Kampman K, Dackis C, Sparkman T, Pettinati H (2008) Cocaine withdrawal symptoms identify "Type B" cocainedependent patients. Am J Addict 17: 60-64.

52. Ahmadi J, Pridmore S, Alimi A, Cheraghi A, Arad A, et al. (2007) Epidemiology of opium use in the general population. Am J Drug Alcohol Abuse 33: 483-491.

53. Ahmadi J, Kampman K, Dackis C (2006) Outcome predictors in cocaine dependence treatment trials. Am J Addict 15: 434-439.

54. Tabei SZ, Heydari ST, Mehrabani D, Shamsina SJ, Ahmadi J, et al. (2006) Current substance use in patients with gastric cancer in Southern Iran. J Cancer Res Ther 2: 182-185.

55. Ahmadi J, Fallahzadeh $H$, Salimi A, Rahimian $M$, Salehi $V$, et al. (2006) Analysis of opium use by students of medical sciences. J Clin Nurs 15: 379-386.

56. Ahmadi J, Tabatabaee F, Gozin Z (2006) Physical trauma and substance abuse: a comparative study on substance abuse in patients with physical trauma versus general population. J Addict Dis 25: 51-63.

57. Ahmadi J, Ahmadi M, Pridmore S, et al. (2005) Substance Use Disorders in Rheumatic Patients. German J Psychiatry 5: 66-69.

58. Ahmadi J, Menzies P, Maany I (2005) Pattern of cocaine and heroin abuse in a sample of Iranian general population. German J Psychiatry 8: 1-4.

59. Ahmadi J, Farrashbandi H, Menzies P (2005) Prevalence of mood and anxiety disorders in a sample of Iranian outpatient opioid addicts. German J Psychiatry 8: 5-7.

60. Ahmadi J, Farrashbandi H, Majdi B (2005) Substance-induced anxiety disorder in opioid dependents. Addictive Disorders \& Their Treatments 1-4.

61. Ahmadi J, Babaee-Beigi M, Alishahi M, Maany I, Hidari T (2004) Twelve-month maintenance treatment of opium-dependent patients. J Subst Abuse Treat 26: 363-366.

62. Ahmadi J, Babaeebeigi M, Maany I, Porter J, Mohagheghzadeh $\mathrm{M}$, et al. (2004) Naltrexone for alcohol-dependent patients. Ir J Med Sci 173: 34-37.

63. Ahmadi J, Majdi B, Mahdavi S, Mohagheghzadeh M (2004) Mood disorders in opioid-dependent patients. J Affect Disord 82: 139-142.

64. Ahmadi J, Farrashbandi H, Moosavinasab M (2004) Treatment of heroin dependence. German J Psychiatry 7: 1-5.

65. Ahmadi J, Pridmor S, Fallahzadeh M (2004) Neurotic scores in medical students. German J Psychiatry 7: 51-55.

66. Ahmadi J, Maharlooy N, Alishahi M (2004) Substance abuse: prevalence in a sample of nursing students. J Clin Nurs 13: 60-64. 
67. Ahmadi J, Alavi M, Alishahi M (2004) Substance Use Disorders in a Sample of Iranian Secondary School Students. Social Indicators Research 65: 355-360.

68. Pridmore S, Skerritt $P$, Ahmadi J (2004) Why do doctors dislike treating people with somatoform disorder? Australas Psychiatry 12: $134-138$.

69. Ahmadi J, Toobaee S, Alishahi M (2004) Depression in nursing students. J Clin Nurs 13: 124.

70. Ahmadi J, Ahmadi K, Ohaeri J (2003) Controlled, randomized trial in maintenance treatment of intravenous buprenorphine dependence with naltrexone, methadone or buprenorphine: a novel study. Eur J Clin Invest 33: 824-829.

71. Ahmadi J (2003) Methadone versus buprenorphine maintenance for the treatment of heroin-dependent outpatients. J Subst Abuse Treat 24: 217-220.

72. Ahmadi J, Toobaee S, Kharras M, Radmehr M (2003) Psychiatric disorders in opioid dependants. Int J Soc Psychiatry 49: 185-191.

73. Ahmadi J, Etminan H, Javanmardi H (2003) Reasons for cessation of opiate use among Iranian opioids dependants. Addictive Disorders \& Their Treatment 2: 9-12.

74. Ahmadi J, Rayisi T, Alishahi M (2003) Analysis of substance use by primary school students. German J Psychiatry 3:56-59.

75. Ahmadi J, Ashkani H, Ahmadi M, Ahmadi N (2003) Twenty-four week maintenance treatment of cigarette smoking with nicotine gum, clonidine and naltrexone. J Subst Abuse Treat 24: 251-255.

76. Ahmadi J, Ahmadi M (2003) Twelve-month maintenance treatment of heroin- dependent outpatients with buprenorphine. J Subst Use. April 8: 39-41.

77. Ahmadi J, Sharifi M (2003) Cannabis abuse in Iran. Ir J Med Sci 172: 46 .

78. Ahmadi J, Arabi H, Mansouri Y (2003) Prevalence of substance use among offspring of opioid addicts. Addict Behav 28 591-595.

79. Ahmadi J, Motamed F (2003) Treatment success rate among Iranian opioid dependents. Subst Use Misuse 38: 151-163.

80. Ahmadi J, Hasani M (2003) Prevalence of substance use among Iranian high school students. Addict Behav 28: 375-379.

81. Ahmadi J, Maany I, Ahmadi M (2003)Treatment of Intravenous Buprenorphine Dependence: A Randomized Open Clinical Trial. German J Psychiatry 6: 23-29.

82. Ahmadi J, Javadpour A (2002) Assessing substance use among Iranian health care students. European J Psychiatry 16: 174-177.

83. Ahmadi J, Bahrami N (2002) Buprenorphine treatment of opiumdependent outpatients seeking treatment in Iran. J Subst Abuse Treat 23: 415-417.

84. Ahmadi J, Samavatt F, Sayyad M, Ghanizadeh A (2002) Various types of exercise and scores on the Beck Depression Inventory. Psychol Rep 90: 821-822.

85. Ahmadi J, Yazdanfar F (2002) Substance use among Iranian university students. The International Journal of Drug Policy 13 507-508.

86. Ahmadi JA (2002) randomized, clinical trial of buprenorphine maintenance treatment for Iranian patients with opioid dependency. Addictive Disorders \& Their Treatments 1: 24-27.
87. Ahmadi J, Benrazavi L (2002) Substance use among Iranian physical patients. The International Journal of Drug Policy 13: 505-506.

88. Ahmadi J, Ostovan M (2002)Substance use among Iranian male students. The International Journal of Drug Policy 13: 511-512.

89. Ahmadi J (2002) Buprenorphine maintenance treatment of heroin dependence: the first experience from Iran. J Subst Abuse Treat 22: 157-159.

90. Ahmadi J, Benrazavi L (2002) Substance use among Iranian nephrologic patients. Am J Nephrol 22: 11-13.

91. Ahmadi J, Ahmadi N (2002) A Double Blind Placebo-Controlled Study of Naltrexone in the Treatment of Alcohol Dependence. German J Psychiatry 5: 85-9.

92. Ahmadi J, Benrazavi L (2002) Substance use among Iranian surgical patients. The International Journal of Drug Policy 13: 509-510.

93. Ahmadi J (2002) A controlled trial of buprenorphine treatment for opium dependence: the first experience from Iran. Drug Alcohol Depend 66: 111-114.

94. Ahmadi J, Benrazavi L (2002) Substance use among Iranian cardiovascular patients. Eur J Med Res 7: 89-92.

95. Ahmadi J, Benrazavi L, Ghanizadeh A (2001) Substance abuse among contemporary Iranian medical students and medical patients. J Nerv Ment Dis 189: 860-861.

96. Ahmadi J, Fakoor A, Pezeshkian P, Khoshnood R, Malekpour A (2001) Substance use among Iranian psychiatric inpatients. Psychol Rep 89: 363-365.

97. Ahmadi J, Khalili $H$, Jooybar R, Namazi N, Mohammadagaei $P$ (2001) Prevalence of cigarette smoking in Iran. Psychol Rep 89: 339-341.

98. Ahmadi J, Ghanizadeh A (2001) Current substance use among Iranian medical students. Indian J Psychiatry 43: 157-161.

99. Ghanizadeh A, Ahmadi J (2000) The MMPI profile of opiate addicts of Iran: evidence from Shiraz. Ann Saudi Med 20: 334-336.

100. Ahmadi J, Ghanizadeh A (2000) Motivations for use of opiates among addicts seeking treatment in Shiraz. Psychol Rep 87: 1158-1164.

101. Ahmadi J, Khalili H, Jooybar R, Namazi N, Aghaei PM (2001) Cigarette smoking among Iranian medical students, resident physicians and attending physicians. Eur J Med Res 6: 406-408.

102. Ahmadi J, Ahmadi M, Pridmore S (2005) Substance Use Disorders in Rheumatic Patients. German J Psychiatry 5: 66-9.

103. Ang-Lee K, Oreskovich MR, Saxon AJ, Jaffe C, Meredith C, et al. (2006) Single dose of 24 milligrams of buprenorphine for heroin detoxification: an open-label study of five inpatients. J Psychoactive Drugs 38: 505-512.

104. Kutz I, Reznik V (2001) Rapid heroin detoxification using a single high dose of buprenorphine. J Psychoactive Drugs 33: 191-193.

105. Anvar M, Ahmadi J, Hamidian S, Ghafaripour S (2016) Female Sexual Dysfunction Among the Wives of Opioid-Dependent Males in Iran Int J High Risk Behav Addict 5: e25435.

106. Ahmadi J, Sahraian A, Shariati S (2015) Delusional disorder joined with opium dependence Sch J App Med Sci 3: 3387-3390. 
107. Ahmadi J, Dastgheib SA, Mowla A, Ahmadzadeh L, Bazrafshan A, et al. (2016) Treatment of Methamphetamine Induced Persistent Psychosis. J Add Pre Med 1: 103.

108. Ahmadi J, Khoddaman AR, Kordian S, Pridmore S (2016) Treatment of an obese opioid dependent with a single dose of $80 \mathrm{mg}$ of buprenorphine: a new opening. Int J Res Rep 2:11-18.

109. Ahmadi J, Ahmadi F, Torabi A, Ahmadi S, Ahmadi F (2016) A single dose of $55 \mathrm{mg}$ of buprenorphine for the treatment of heroin dependence: a new result. J Haminiz Med Res and HIth Sci 3: 1-7.

110. Ahmadi J (2016) Methylphenidate in the treatment of methamphetamine withdrawal Craving: a novel outcome. J Drug Abuse 1:12. 